\title{
On the Adsorption of Sulfate on Low Miller Index Rh(hkl) Electrodes: an in Situ Vibrational Analysis
}

\author{
Ines R. de Moraes and Francisco C. Nart* \\ Instituto de Química de São Carlos, Universidade de São Paulo, C. P. 780, 13560-970, São Carlos - SP, Brazil
}

\begin{abstract}
A adsorção de íon sulfato em eletrodos de $\mathrm{Rh}(111), \mathrm{Rh}(100)$ e $\mathrm{Rh}(110)$ foi estudada utilizandose a técnica de espectroscopia de FTIR por reflectância in situ. Foi observada somente uma banda vibracional localizada acima de $1200 \mathrm{~cm}^{-1}$ para as três superfícies com baixo índice de Miller e uma banda fraca em $960 \mathrm{~cm}^{-1}$ para o sulfato adsorvido em Rh(111). A banda forte acima de $1200 \mathrm{~cm}^{-1}$ é dependente do potencial com uma variação de $50 \mathrm{~cm}^{-1} \mathrm{~V}^{-1}$. Não foram observadas diferenças espectrais ao se variar a acidez da solução de forma a gerar soluções contendo sulfato ou sulfato ácido. Este resultado é interpretado em termos de uma dissociação completa dos íons, produzindo somente $\mathrm{SO}_{4}{ }^{2-}$ adsorvido. A orientação da superfície afeta somente a quantidade de espécies sulfato adsorvidas. Parece que o mesmo tipo de adsorbato é encontrado em $\mathrm{Rh}(111), \mathrm{Rh}(110)$ e $\mathrm{Rh}(100)$.
\end{abstract}

The adsorption of sulfate ion on $\mathrm{Rh}(111), \mathrm{Rh}(100)$ and $\mathrm{Rh}(110)$ electrodes was studied using in situ FTIR reflection spectroscopy. For wavenumbers above $1200 \mathrm{~cm}^{-1}$, only one strong vibrational band is observed for adsorbed sulfate on the three low index rhodium surfaces. A weak band at $960 \mathrm{~cm}^{-1}$ is also observed for $\mathrm{Rh}(111)$. The strong band above $1200 \mathrm{~cm}^{-1}$ is potential dependent with a tuning rate of $50 \mathrm{~cm}^{-1} \mathrm{~V}^{-1}$. No differences were observed upon changing the solution acidity in order to provide sulfate or bisulfate in solution. This result is interpreted in terms of complete dissociation of the ions, giving only adsorbed $\mathrm{SO}_{4}{ }^{2-}$. The surface orientation affects only the amount of the adsorbed sulfate species. It seems that the same adsorbed sulfate is present on $\mathrm{Rh}(111), \mathrm{Rh}(110)$ and $\mathrm{Rh}(100)$.

Keywords: electrochemical interfaces, reflection spectroscopy, adsorption

\section{Introduction}

Adsorption of anions is of central interest in electrochemistry, especially of those which are used as supporting electrolytes in electrochemical systems. The sulfate species is the most studied adsorbed anion on electrodes, since sulfuric acid is one of the most commonly used supporting electrolytes, especially in the study of single crystal electrodes. Furthermore, the adsorbed anions may play a role on the kinetics of electrochemical oxidation reactions.

The adsorption of sulfate and other oxyanions experimented a renewed interest with the introduction of auxiliary techniques in electrochemistry, such as in situ FTIR spectroscopy $^{1}$, radioactive labeling ${ }^{2}$ and in situ scanning tunneling microscopy $(\mathrm{STM})^{3-5}$.

Vibrational studies of sulfate adsorbed on single crystal metal electrodes are reported for $\operatorname{Pt}(111)^{6-9}, \operatorname{Pt}(100)^{10,11}$, $\operatorname{Pt}(110)^{12}, \mathrm{Au}(111)^{3,13}, \mathrm{Au}(100)$ and $(110)^{14}$ and $\mathrm{Rh}(111)^{15,16}$. Single crystal surfaces constitute interesting model systems for the study of adsorbed sulfate, especially

\footnotetext{
*e-mail: nart@iqsc.sc.usp.br
}

using in situ FTIR, since it permits to establish some correlation between the surface crystallography and the observed vibrational features. In spite of some controversy in the literature, the vibrational characterization of adsorbed sulfate on different surfaces helps the understanding of the structure and bonding of sulfate ions to the electrode surface. Additional studies on new systems will help to clarify controversial points in the interpretation of the spectra.

The common characteristic for adsorbed sulfate on $\operatorname{Pt}(111)^{6-9}$ and $\mathrm{Au}(111)^{3,13}$ is that the spectroscopic features do not depend on the solution $\mathrm{pH}$, i.e. it is insensitive to the presence of bisulfate or sulfate in solution. On the other hand, adsorbed sulfate on other surfaces, like $\operatorname{Pt}(100)^{10,11}$, $\mathrm{Pt}(110)^{12}$ and $\mathrm{Au}(110)^{14}$ produces different vibrational features depending on the $\mathrm{pH}$. These results reveal the role of the surface topography on the structure and the nature of adsorbed sulfate.

While the adsorption of sulfate on Pt and Au single crystal is well documented, data of sulfate ion adsorbed on $\mathrm{Rh}$ single crystal electrodes are scarce. Shyngaya et al. ${ }^{15,16}$, in a study with different $\mathrm{M}(111)$ electrodes, reported vibrational spectroscopic data for adsorbed sulfate species 
on $\mathrm{Rh}(111)$ electrodes. A quite remarkable similarity with the bands observed for $\mathrm{Pt}(111)$ is observed. Zelenay et al. ${ }^{17}$ reported cyclic voltammetry and radioactive labeling of adsorbed sulfate on $\mathrm{Rh}(111)$ single crystals and polycrystalline $\mathrm{Rh}$ electrodes. They found that the total coverage was 40 per cent of the total theoretical maximum coverage on $\mathrm{Rh}(111)$ and that the adsorbed sulfate is more stable on $\mathrm{Rh}(111)$ than on the other low Miller index surfaces of Rh.

STM data on sulfate adsorbed on $\mathrm{Rh}(111)$ has been reported recently ${ }^{4}$, showing that the adsorbed sulfate forms a $\sqrt{3} x \sqrt{7}$ structure, similar to that found for $\mathrm{Au}(111)^{3}$ and $\mathrm{Pt}(111)^{5}$. It is noteworthy that the surface coverage of 0.2 suggested by this structure is the same for $\mathrm{Au}(111), \mathrm{Pt}(111)$ and $\mathrm{Rh}(111)$ and it is in good agreement with other techniques, such as radiotracer assay ${ }^{15}$.

To our knowledge, the adsorption of sulfate on $\mathrm{Rh}(100)$ and $\mathrm{Rh}(110)$ has not been reported so far. The study of the adsorption of sulfate on those surfaces is also important in order to accomplish a more general view of the vibrational characteristics of adsorbed sulfate species on electrochemical interfaces. More specifically, we are interested in surfaces which do not match very well a threefold coordination for the adsorbed sulfate.

In the present work we report vibrational data of adsorbed sulfate adlayers on the low Miller index of Rh single crystal surfaces. We will bring into focus previously published data on sulfate adsorbed on $\mathrm{Pt}(111)$ and $\mathrm{Au}(111)$ to compare with our data of $\mathrm{Rh}(111)$. Our objective is to understand the surface chemistry of adsorbed sulfate using in situ vibrational spectroscopy.

\section{Experimental}

All solutions were prepared with Merck Suprapur reagents and Millipore Milli-Q purified water.

The low Miller index Rh(hkl) single crystal (99.999\%) was of a cylindrical form with a diameter of $10 \mathrm{~mm}$ and obtained from Metal Crystal \& Oxides (Cambridge, UK). The final preparation of the rhodium single crystal consisted of annealing the $\mathrm{Rh}$ single crystal in gas flame for about $2-3 \mathrm{~s}$ at a temperature of about $1300^{\circ} \mathrm{C}$, cooling in a stream of $\mathrm{Ar}+\mathrm{H}_{2}$ and rapid-quenching in ultrapure water. The crystal was transferred rapidly to the spectroelectrochemical cell protected by a drop of water to avoid contamination.

Before each experiment the electrode was cycled electrochemically in the base electrolyte in the potential range $0.05-0.8 \mathrm{~V}$ to control the quality of the crystal surface and the solution. In order to avoid disordering of the crystal surface, the maximum potential used was $0.8 \mathrm{~V}$, a potential prior the rhodium oxidation.
A BOMEM DA-8 spectrometer equipped with a $\mathrm{L}-\mathrm{N}_{2}$ cooled MCT detector was used for the in situ experiments. The spectroelectrochemical cell was made of PTFE ${ }^{\mathrm{TM}}$ with a $\mathrm{CaF}_{2}$ transparent flat window placed at the bottom of the cell. A Pt ring was used as the auxiliary electrode and a Pd mesh loaded with hydrogen $\left(\mathrm{Pd} / \mathrm{H}_{2}\right)$ was used as a reference electrode. All potentials are referred to the $\mathrm{Pd} / \mathrm{H}_{2}$ electrode.

The procedure followed for the accumulation of the spectra was already described in detail in previous publications ${ }^{10}$. Typically 10000 scans were collected for each potential. Since 10000 scans take a long time, the spectra were collected by stepping ten times the potential between a reference and a sample potential and 1000 scans were collected at the reference and sample potential. Such number of scans was necessary taking into account the small amount of adsorbed ions at the electrode surface and the reduced intensity of the reflection-absorption bands due to the use of a flat window.

\section{Results}

\section{Effect of solution acidity}

When analyzing the spectra obtained in situ, it is necessary to take into account that the spectra reported correspond to the ratio of two spectra obtained at two different electrode potentials (the sample potential and the reference potential). The reference potential is taken where no sulfate adsorption occurs. The spectral information coming from the adsorbed ions will be coupled with the spectral information coming from the ions depleted from the solution upon adsorption. This happens because the thin layer of solution held between the electrode and the transparent window can be considered practically uncoupled from the bulk solution. No fast diffusion of the ions to the thin solution layer will occur in the timescale of the experiment. Therefore, positive-going bands will correspond to species depleted from the optical path and the negative-going bands, to species formed at the sample potential.

The spectra of adsorbed sulfate at $\mathrm{pH} 3$ and 0.2 at the maximum coverage, where $\mathrm{SO}_{4}{ }^{2-}$ and $\mathrm{HSO}_{4}{ }^{-}$predominate, respectively ${ }^{18}$ are shown for $\mathrm{Rh}(111)$ (Figure 1) and for $\mathrm{Rh}(100)$ (Figure 2). For the sulfate adsorbed from a solution containing $\mathrm{SO}_{4}{ }^{2-}$ ions, three bands can be clearly distinguished (Figure 1a). One positive-going band is centered at $1100 \mathrm{~cm}^{-1}$ and two negative-going bands are located at $1247 \mathrm{~cm}^{-1}$ and $960 \mathrm{~cm}^{-1}$. These bands are in good agreement with those reported for sulfate adsorbed on $\mathrm{Rh}(111)$ in sulfuric acid solutions ${ }^{16}$. As already discussed in previous publications 6 , the positive feature at $1100 \mathrm{~cm}^{-1}$ is 


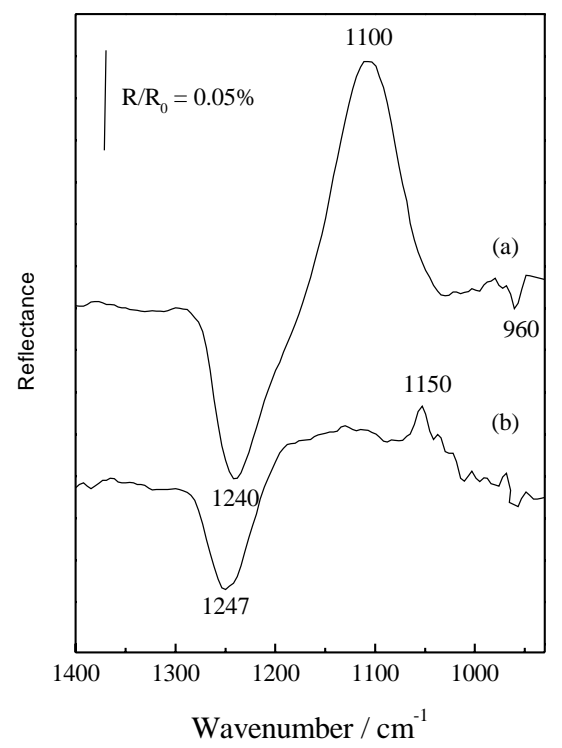

Figure 1. p-polarized in situ FTIR reflectance spectra of a single crystal $\mathrm{Rh}$ (111) electrode in solution of: (a) $\mathrm{pH} 3\left(0.5 \mathrm{~mol} \mathrm{~L}^{-1} \mathrm{KF} / 0.69 \mathrm{~mol} \mathrm{~L}^{-1}\right.$ $\mathrm{HF})\left(\right.$ b) $\mathrm{pH} 0.2(7 \mathrm{~mol} \mathrm{~L}-1 \mathrm{HF})$ containing $2.5 \times 10^{-2} \mathrm{~mol} \mathrm{~L}^{-1} \mathrm{Na}_{2} \mathrm{SO}_{4}$. Reference spectrum was obtained at $0.0 \mathrm{~V}$. Spectra were obtained at potentials as indicated in the figure.

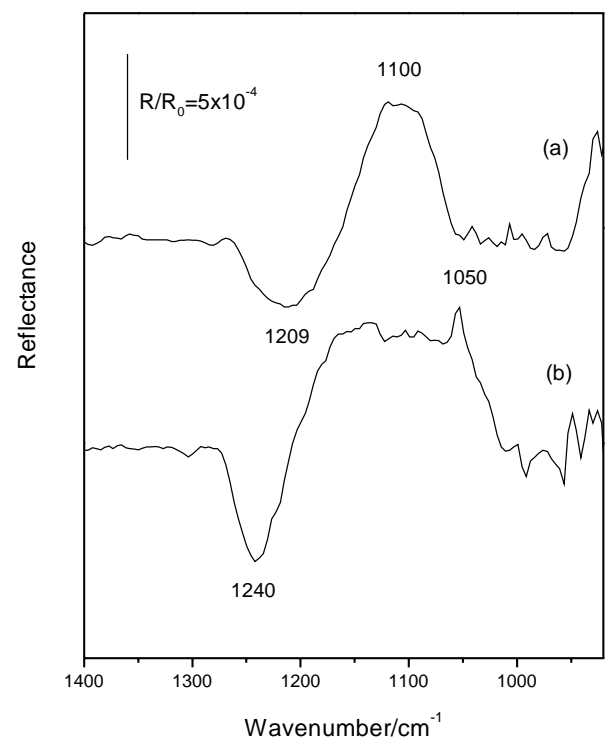

Figure 2. p-polarized in situ FTIR reflectance spectra from a single crystal $\mathrm{Rh}(100)$ electrode in solution of: (a) $\mathrm{pH} 3\left(0.5 \mathrm{~mol} \mathrm{~L}^{-1} \mathrm{KF} / 0.69 \mathrm{~mol} \mathrm{~L}^{-1}\right.$ $\mathrm{HF})\left(\right.$ b) $\mathrm{pH} 0.2(7 \mathrm{~mol} \mathrm{~L}-1 \mathrm{HF})$ containing $2.5 \times 10^{-2} \mathrm{~mol} \mathrm{~L}^{-1} \mathrm{Na}_{2} \mathrm{SO}_{4}$. Reference spectrum was obtained at $0.0 \mathrm{~V}$. Spectra were obtained at potentials as indicated in the figure.

due to the dissolved $\mathrm{SO}_{4}{ }^{2-}$, which presents only one active stretching vibration located at this wavenumber. The two negative features correspond to the $\mathrm{S}-\mathrm{O}$ stretching vibrations of adsorbed sulfate. The solution species spectra were checked using s-polarized light (data not shown) and only the positive-going band at $1100 \mathrm{~cm}^{-1}$ was observed, corroborating the proposal that this band corresponds to the depletion of the sulfate in solution, since the s-polarized light is active only to solution species. ${ }^{1}$ The spectrum for the adsorbed sulfate on $\mathrm{Rh}(100)$ (Figure 2a) does not display very clearly the band at $960 \mathrm{~cm}^{-1}$, since for this electrode the signal to noise ratio is too low to allow the distinction of this weak band.

For solutions of $\mathrm{pH} 0.2$ (Figures 1 and 2), again, two negative-going bands can be distinguished at 1239 and 960 $\mathrm{cm}^{-1}$, for the two electrodes. These bands are at approximately the same positions of those observed for $\mathrm{pH}$ 3. As already observed for adsorbed sulfate on $\operatorname{Pt}(111)^{6-9}$ and $\mathrm{Au}(111),{ }^{3,13}$ the vibrational feature of sulfate adsorbed on $\mathrm{Rh}(111)$ is independent of the presence of sulfate or bisulfate in solution. Very likely, adsorbed bisulfate species from very acid solutions undergoes complete dissociation when adsorbed on these surfaces. Therefore, only $\mathrm{SO}_{4}{ }^{2-}$ is adsorbed on $\mathrm{Rh}(111)$. For sulfate ions adsorbed on $\mathrm{Rh}(100)$ electrodes the band intensity is smaller than on $\mathrm{Rh}(111)$ electrodes and therefore, the band center is observed at lower energy. For the very acidic solution, bisulfate in solution has a stretching mode at $1200 \mathrm{~cm}^{-1}$, thus partially overlapping with the band for the adsorbed species, which is centered at $1240 \mathrm{~cm}^{-1}$. The band center is therefore disturbed by the positive going band and probably the actual value is somewhat different of that observed.

\section{Effect of the surface geometry}

The spectra of adsorbed sulfate at maximum coverage (0.3 V) on $\mathrm{Rh}(111), \mathrm{Rh}(100)$ and $\mathrm{Rh}(110)$ are shown in Figure 3. For sulfate species adsorbed on $\mathrm{Rh}(100)$ and $\mathrm{Rh}(110)$, the spectra are qualitatively very similar to that of $\mathrm{Rh}(111)$. However, the integrated band intensities are, for the sulfate adsorbed on $\mathrm{Rh}(100)$ and $\mathrm{Rh}(110), c a .1 / 3$ of the intensity for sulfate adsorbed on $\mathrm{Rh}(111)$. The band half width for the adsorbed sulfate at saturation coverage on $\mathrm{Rh}(100)$ and $\mathrm{Rh}(110)$ is $57 \mathrm{~cm}^{-1}$, while for $\mathrm{Rh}(111)$ the band half width is $42 \mathrm{~cm}^{-1}$. A broader band means that for $\mathrm{Rh}(100)$ and $\mathrm{Rh}(110)$ the sulfate adlayer is not as well organized as in the case of $\mathrm{Rh}(111)$ surfaces. It might be that the organization needs a minimum coverage in order to compress the adsorbed species into an ordered layer. Unfortunately no structural or thermodynamic data on adsorbed sulfate on $\mathrm{Rh}(100)$ and $\mathrm{Rh}(110)$ is found in the literature to compare with the total coverage and adlayer ordering.

In Figures 4 (a) and (b) the change of the surface coverage indicated by the integrated band intensity is shown for the sulfate adsorbed on $\mathrm{Rh}(111)$ in a solution of $\mathrm{pH} 3$, along with a voltammetric curve for sulfate adsorbed on $\mathrm{Rh}(111)$ in this solution. The adsorption starts at $c a .0 .1 \mathrm{~V} \mathrm{vs}$. $\mathrm{Pd} / \mathrm{H}_{2}$, 
grows up very sharply reaching a plateau going from 0.3 to $0.6 \mathrm{~V}$ and decreases in the potential range where the $\mathrm{OH}^{-}$ begin to be adsorbed, as observed in the voltammetry in Figure 4 (b). This result is in a very good qualitative agreement with the data reported by Wieckowski and coworkers, using radiotracer labeling ${ }^{17}$, to quantify the amount of adsorbed sulfate on $\mathrm{Rh}(111)$ electrodes.

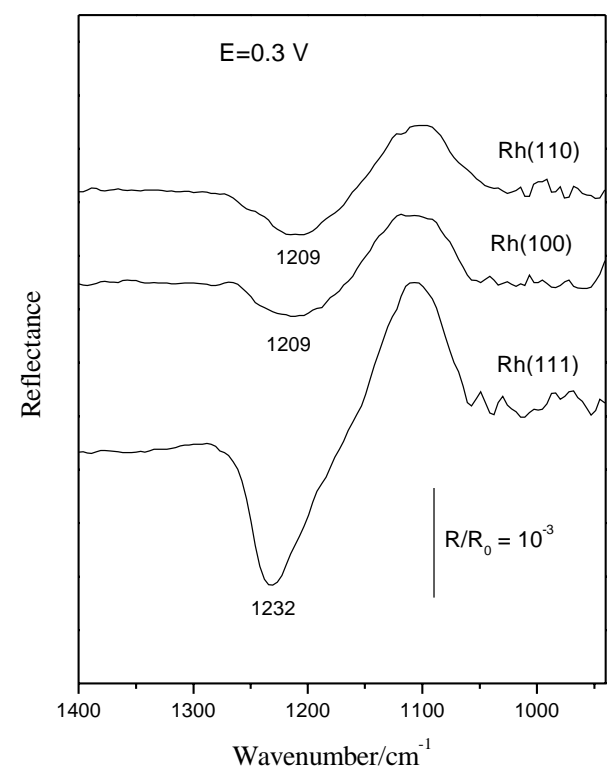

Figure 3. p-polarized in situ FTIR reflectance spectra from single crystal $\mathrm{Rh}(100), \mathrm{Rh}(110)$ and $\mathrm{Rh}(111)$ electrodes at the maximum coverage in $0.5 \mathrm{~mol} \mathrm{~L}^{-1} \mathrm{KF} / 0.69 \mathrm{~mol} \mathrm{~L}^{-1} \mathrm{HF}$ base solution (pH 3) containing $2.5 \mathrm{x}$ $10^{-2} \mathrm{~mol} \mathrm{~L}^{-1} \mathrm{Na}_{2} \mathrm{SO}_{4}$. Reference: $0.0 \mathrm{~V}$. Spectra were obtained at potentials as indicated in the figure.

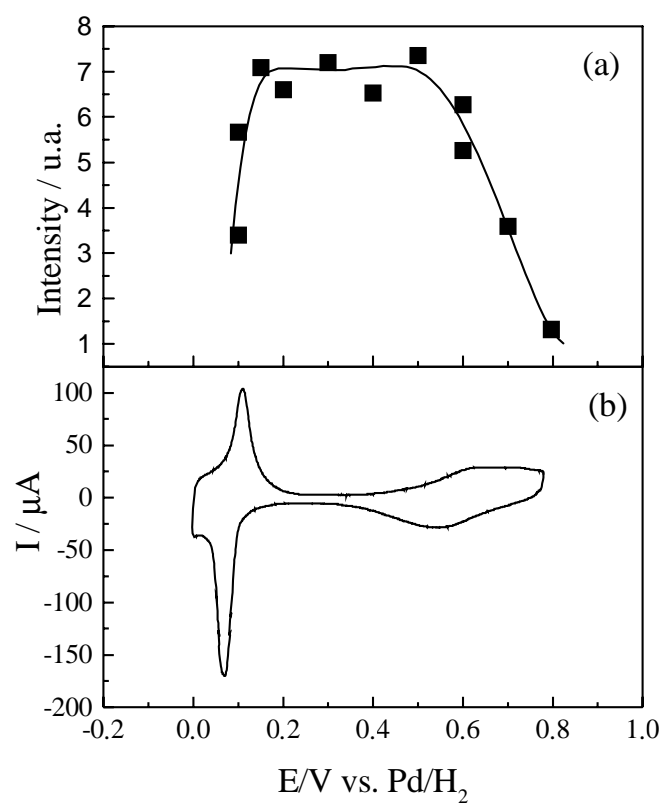

Figure 4. Potential dependence of the integrated band intensity of the sulfate $\left(\sim 1200 \mathrm{~cm}^{-1}\right)$ (a) and the cyclic voltammogram of $\mathrm{Rh}(111)$ (b) in $0.5 \mathrm{~mol} \mathrm{~L}^{-1} \mathrm{KF} / 0.69 \mathrm{~mol} \mathrm{~L}^{-1} \mathrm{HF}$ base solution ( $\mathrm{pH} 3$ ) containing $2.5 \times 10^{-}$ $2 \mathrm{~mol} \mathrm{~L}^{-1} \mathrm{Na}_{2} \mathrm{SO}_{4}$; scan rate for the cyclic voltammogram: $50 \mathrm{mV} \mathrm{s}^{-1}$. (The line is the best polynomial fit to the points)
The change in band intensity of adsorbed sulfate on $\mathrm{Rh}(100)$ is shown with the cyclic voltammetry in Figure 5 (a) and (b), respectively. The adsorption starts at ca. $0.1 \mathrm{~V}$, during the hydrogen desorption process. A maximum of sulfate species adsorption is observed at the end of the double layer and the band intensity decreases when the current of the voltammogram starts to increase smoothly, indicating the onset of oxide formation. Though not shown here, the adsorbed sulfate on $\mathrm{Rh}(110)$ presents practically the same behavior. It is noteworthy to observe that the onset of adsorption occurs at very low potentials $(0.1 \mathrm{~V})$, in contrast with $\mathrm{Pt}^{6-12}$ and $\mathrm{Au}{ }^{13,14}$ electrodes.

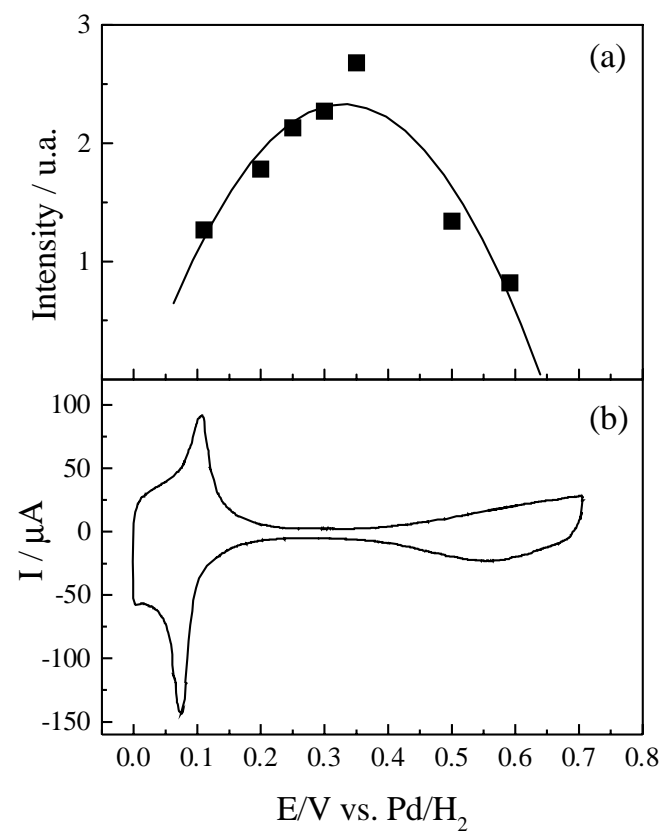

Figure 5. (a) Potential dependence of the integrated band intensity of the adsorbed sulfate on $\operatorname{Rh}(100)$ (band centered at $\sim 1200 \mathrm{~cm}^{-1}$ ) and (b) cyclic voltammogram of $\mathrm{Rh}(100)$ in $0.5 \mathrm{~mol} \mathrm{~L}^{-1} \mathrm{KF} / 0.69 \mathrm{~mol} \mathrm{~L}^{-1} \mathrm{HF}$ base solution ( $\mathrm{pH} 3$ ) containing $2.5 \times 10^{-2} \mathrm{~mol} \mathrm{~L}^{-1}$; scan rate: $50 \mathrm{mV} \mathrm{s}^{-1}$. (The line is the best polynomial fit to the points)

The main feature of the adsorbed sulfate (strong negativegoing band) is shifted to higher energies for more positive applied potentials, as can be seen from the plot of the band center wavenumber as a function of the applied potential (Figure 6). As discussed before, this feature is due to a coupling of two different effects: (i) the increase in the ion surface density ${ }^{6}$ and (ii) the Stark effect ${ }^{19}$ due to the strong electric field applied at the electrochemical interface. The change of the band center wavenumber for adsorbed sulfate species on $\mathrm{Rh}(111)$ in both solution pHs is shown in Figure 3. It is interesting that for sulfate adsorbed on $\mathrm{Rh}(111)$, in the 0.3-0.5 V range, the surface coverage does not change (Figure $2 b)$. Thus the band shift in this range can be assigned only to the effect of the electric field. A linear change of the band center with potential is observed with a dv/dE of $50 \mathrm{~cm}^{-1} \mathrm{~V}^{-1}$. 


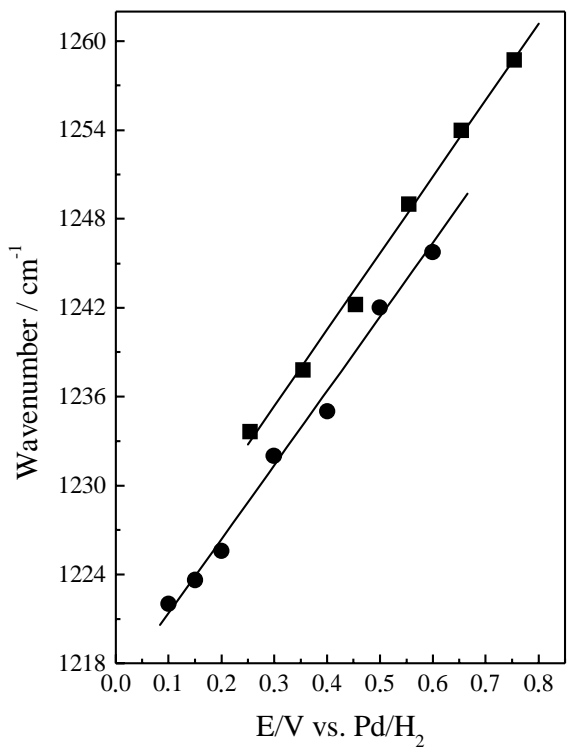

Figure 6. Plot of band center wavenumber for the main feature of adsorbed sulfate on $\mathrm{Rh}(111)$ electrode. (ם) $\mathrm{HSO}_{4}{ }^{-}$in solution and (O) $\mathrm{SO}_{4}{ }^{2-}$ in solution. (The line is the best quadratic fit to the points)

\section{Discussion}

The surface selection rule limits the observable bands to those with a non vanishing component of the dipole moment perpendicular to the surface. Sulfate ions have a tetrahedral symmetry when free in solution. Depending on the coordination to the surface, the symmetry for the adsorbed sulfate can be $\mathrm{C}_{3 \mathrm{v}}$, for the one-fold and three-fold coordination and $\mathrm{C}_{2 \mathrm{v}}$, for a two-fold coordination. Both $\mathrm{C}_{3 \mathrm{v}}$ and $\mathrm{C}_{2 \mathrm{v}}$ symmetries will present only two observable stretching bands, according to the surface selection rule. These bands are the symmetric $\mathrm{A}_{1}$ vibrations, which have the dynamic dipole moment in the same direction of the symmetry axis. With this strong limitation imposed by the surface selection rule, it is practically impossible, from the spectroscopic data alone, to deduce the adsorption geometry for the adsorbed sulfate species. In previous publications, it has been assumed that sulfate ions (or bisulfate ions) are coordinated to the $\mathrm{Pt}(111)$ surface by three oxygen atoms (three-fold coordination) $)^{6,8}$, since this surface matches well such a geometry for the adsorbed sulfate. Comparison with the adsorption of sulfate on $\operatorname{Pt}(100)$ suggested that this assumption was quite reasonable. The sulfate adsorbed on $\mathrm{Pt}(100)^{10}$ and also on $\mathrm{Pt}(110)^{12}$ surfaces present different vibrational features to those observed for $\mathrm{Pt}(111)$. On Pt(100) and $\mathrm{Pt}(110)$ the adsorbed sulfate ions present two bands at $1180-1220 \mathrm{~cm}^{-1}$ and $1100 \mathrm{~cm}^{-1}$. However, this is not the case for the adsorbed sulfate on rhodium single crystal electrodes, where the vibrational bands present qualitatively the same features for the three surfaces. Only the band energy and band width change for the different surfaces. The band energy usually is a complex function of the surface coverage (dipole-dipole and lateral chemical coupling), of the electric field at the electrochemical interface, the coordination to the surface and of the bonding of the adsorbate to the metal surface. From the band intensities for the adsorbed sulfate on the different rhodium surfaces, it is clear that the surface coverage is much higher for $\mathrm{Rh}(111)$. STM measurements of adsorbed sulfate on $\operatorname{Rh}(111)^{4}$ surfaces display a $\sqrt{3} x \sqrt{7}$ structure, as in the case of sulfate adsorbed on $\mathrm{Au}(111)^{3}$ and $\mathrm{Pt}(111) .{ }^{5}$ Since no independent measurements of the surface coverage are known for $\mathrm{Rh}(110)$ and $\mathrm{Rh}(100)$, it is difficult to estimate the differences in lateral coupling on the band position for the different surfaces. Moreover, the lack in the knowledge of the potential of zero charge for rhodium electrodes makes it difficult to evaluate the effect of the applied electric field for the different surfaces and consequently to analyze the effect of sulfate coordination on the different vibrational features for adsorbed sulfate at the rhodium surfaces. Furthermore, different bonding to the surface can induce differences at the dynamic dipole moment and therefore on the band intensity.

The most significant result of this study is the observation that the adsorbed sulfate species present the same vibrational features independent of $\mathrm{pH}$ for $\mathrm{Rh}(111)$ and $\mathrm{Rh}(100)$ electrode surfaces. These results show that on rhodium, the adsorbed species does not depend on the nature of the ion in solution. Thus, it is clear that either $\mathrm{HSO}_{4}{ }^{-}$is completely dissociated, or $\mathrm{SO}_{4}{ }^{2-}$ is protonated on the surface. It is worthwhile to note that the same results have been reported for the adsorbed sulfate species on $\operatorname{Pt}(111)^{6}$ and on $\mathrm{Au}(111)^{3,13}$ electrodes. The chemical identity of the adsorbed sulfate species on noble metal electrode surfaces has been the subject of some controversy in the literature. Studies of adsorbed sulfate from sulfuric acid solution at $\mathrm{pH} \approx 1$ on $\mathrm{Pt}(111)$ electrodes concluded for adsorbed bisulfate species, since bisulfate is the predominant species in solution. However, other studies using solutions with different acidity reported the same vibrational features for the adsorbed species originated from very acid solutions (mostly containing $\mathrm{HSO}_{4}^{-}$) and solutions containing only minor amounts of $\mathrm{HSO}_{4}{ }^{-}$. Shyngaya et al. used Ultra-High-Vacuum (UHV) models to identify the chemical nature of the adsorbed sulfate species on $\mathrm{Pt}(111)^{15}$ and $\mathrm{Au}(111) .{ }^{16} \mathrm{SO}_{3}$ is dosed on a pre-deposited water layer at $100 \mathrm{~K}$. Upon dosing $\mathrm{SO}_{3}$ the water was desorbed at different temperatures and the infrared spectra was then acquired. They observed two bands (1233 and $953 \mathrm{~cm}^{-1}$ ) upon desorbing water at $190 \mathrm{~K}$ and three bands (1276, 1043 and $\left.941 \mathrm{~cm}^{-1}\right)$ upon desorbing water at $260 \mathrm{~K}$. Based on the fact that three bands are 
present for the surface with less water, they propose that bisulfate was converted into sulfuric acid molecules tilted on the surface. The tilted configuration of the molecule is necessary to account for the third band, since only two bands are allowed by the surface selection rule for the sulfuric acid adsorbed with the main axis perpendicular to the surface. However, a more detailed study using deuterated water is missing and a definitive assignment can not be made. In sulfuric acid solution they found similar vibrational features for $\mathrm{Pt}(111)$ and concluded that bisulfate is adsorbed at low potentials and sulfuric acid at high potentials. On $\mathrm{Au}(111)$, Shyngaya et al. ${ }^{16}$ suggested that a mixture of sulfate and bisulfate ions are adsorbed based on the evolution of two bands at 1171 and $1044 \mathrm{~cm}^{-1}$ to 1246 and $1041 \mathrm{~cm}^{-1}$ for a more dehydrated overlayer. Again, the lack of a detailed isotopic study prevents an unequivocal assignment of the bands observed. Similar vibrational features were found for sulfate species adsorbed on $\mathrm{Au}(111)$ in sulfuric acid solutions. Although the UHV model could give a clear-cut vibrational assignment to adsorbed sulfate species, the studies by Shyngaya et al. are not conclusive.

The argument invoked in favor of the dissociation of bisulfate on the surface is that on $\mathrm{Au}(111)$ the adsorption of sulfate species started at potentials more positive than the potential of zero charge. Indeed, the adsorption of sulfate species on $\mathrm{Au}(111)$ starts at $c a$. $0.7 \mathrm{~V},{ }^{13}$ while the $\mathrm{E}_{\mathrm{pzc}}$ for $\mathrm{Au}(111)$ in sulfuric acid solutions is $c a .0 .4 \mathrm{~V} .{ }^{18}$ Recently the potential of zero charge for $\mathrm{Pt}(111)$ electrodes was re-discussed and it has been found that the $\mathrm{E}_{\mathrm{pzc}}$ in a $\mathrm{HClO}_{4} 0.1 \mathrm{~mol} \mathrm{~L}^{-1}$ solution is $0.3( \pm 0.2 \mathrm{~V} \text { vs SHE })^{19}$. The onset of sulfate species adsorption on $\mathrm{Pt}(111)$ is at $c a .0 .45 \mathrm{~V}$ vs. SHE, ${ }^{6}$ thus at potentials more positive than the $\mathrm{E}_{\mathrm{pzc}}$. It seems to be a general trend that sulfate ions are adsorbed at positively charged surfaces and the dissociation of the $\mathrm{HSO}_{4}{ }^{-}$is not unlikely. The potential of zero charge for rhodium single crystal electrodes is unknown, but it is very likely that on rhodium electrodes the sulfate species are also adsorbed at potentials more positive than the $\mathrm{E}_{\mathrm{pzc}}$. In this case, it is reasonable to suppose that on $\mathrm{Rh}$ (111) electrodes the adsorbed species is $\mathrm{SO}_{4}{ }^{2-}$, irrespective of the solution acidity.

\section{Acknowledgments}

The authors would like to acknowledge FAPESP and $\mathrm{CNPq}$ for financial support

\section{References}

1. Iwasita, T.; Nart, F. C. Prog. Surf. Sci. 1997, 55, 271.

2. Wieckowski A. Modern Aspects of Electrochemistry, R. E. White, J. O'M Bockris and B. E. Conway (Eds.), Vol. 21, Plenum Press, New York, 1990, p. 65.

3. Edens, G. J.; Gao, X.; Weaver, M. J., J. Electroanal. Chem. 1994, 375, 347.

4. Wan, L. S.; Yau, S.; Itaya, K. J. Phys. Chem. 1995, 99, 9507.

5. Funtikov, A. M.; Linke, U.; Stimming, U.; Vogel, R. Surf. Sci. 1995, 324, L343.

6. Nart, F. C.; Iwasita, T.; Weber, M. Electrochim. Acta 1994, 39, 961.

7. Sawatari, Y.; Inukai, J.; Ito, M. J. Electron Spectrosc. Relat. Phenom. 1993, 64/65, 515.

8. Faguy, P. W.; Markovic, N.; Adzic, R. R.; Fierro, C. A.; Yeager, E. B. J. Electroanal. Chem. 1990, 289, 245.

9. Faguy, P. W.; Marinkovic, N. S.; Adzic, R. R. J. Electroanal, Chem. 1996, 407, 209.

10. Nart, F. C.; Iwasita, T.; Weber, M. Electrochim. Acta 1994, 39, 2093.

11. Faguy, P. W.; Markovic, N.; Ross Jr., P. N. J. Electrochem. Soc. 1993, 140, 1638.

12. Iwasita T.; Nart, F. C.; Rodes, A.; Pastor, E.; Weber, M. Electrochim. Acta 1995, 40, 53.

13. Moraes, I. R.; Nart, F. C. J. Electroanal. Chem. 1999, 461, 110.

14. Moraes, I.R.; da Cunha, M.C.P.M.; Nart, F.C. J. Braz. Chem. Soc. 1996, 7, 453.

15. Shyngaya, Y.; Ito, M. Electrochim. Acta 1998, 44, 745.

16. Shyngaya, Y.; Ito, M. J. Electroanal. Chem. 1999, 467, 299.

17. Zelenay, P.; Horanyi, G.; Rhee, C. K.; Wieckowski, A. J. Electroanal. Chem. 1991, 300, 499.

18. Nart, F. C.; Iwasita, T. J. Electroanal, Chem. 1992, 322, 289.

19. Kolb, D. M. Prog. Surf. Sci. 1996, 51, 173.

20. Weaver, M. J. Langmuir 1998, 14, 3932.

Received: June 21, 2000

Published on the web: January 20, 2001

FAPESP helped in meeting the publication costs of this article. 